\title{
Reseña. Eleazar Humberto Guerra de la Huerta. Narración, experiencia y sujeto. Estrategias textuales en siete autobiografías mexicanas. Ciudad de México: Bonilla Artigas, 2016.
}

Hace cinco décadas que Emmanuel Carballo se dio a la tarea de publicar una interesante colección de autobiografías bajo el nombre genérico de Nuevos escritores mexicanos del siglo XX presentados por sí mismos. El proyecto convocó a once escritores "cuyos trabajos literarios empezaban a mostrar su valor e incipientemente aportaban elementos para su inclusión canónica" (Guerra de la Huerta 18; en adelante, solo indico la página). En libritos de alrededor de 60 páginas cada uno, entre 1966 y 1967 se presentaban a sí mismos José Agustín, Salvador Elizondo, Juan García Ponce, Vicente Leñero, Juan Vicente Melo, Tomás Mojarro, Carlos Monsiváis, Marco Antonio Montes de Oca, Raúl Navarrete, Sergio Pitol y Gustavo Sainz; otros autores, como José Emilio Pacheco y Fernando del Paso, quienes también fueron convocados y publicitados en la colección, finalmente no entregaron el texto que se les invitó a presentar.

El proyecto de Carballo no fue único, porque de manera peculiar coincidió con la aparición en 1966 de Los narradores ante el público (reeditada por Ficticia en 2012). Esta obra recogía los testimonios sobre sí que un año antes, entre junio y 
noviembre de 1965, una veintena de autores había presentado en el Palacio de Bellas Artes. A diferencia de la selección de Carballo, Los narradores ante el público incluía a autores de larga trayectoria y a otros más jóvenes, como Monsiváis y José Emilio Pacheco (lo cual quizá explicaría por qué Pacheco no participó en el proyecto de Carballo). El objetivo de los testimonios orales era hablar brevemente de la infancia de los autores, de su vocación, de su contexto y lecturas, es decir, elaborar una pequeña autobiografía. Se realizó una segunda ronda de presentaciones en 1966, donde participaron otros autores más. Resulta de interés señalar la coincidencia de algunos nombres entre el proyecto de Carballo y este de Bellas Artes, a cargo de Antonio Acevedo Escobedo: en 1965, García Ponce, Melo, Leñero, Monsiváis; en 1966, Elizondo, Mojarro, Sainz.

Las elaboraciones autobiográficas de este abanico de autores en los proyectos editoriales de Carballo y Acevedo resultan ahora de interés desde el marco teórico de las escrituras del yo, que reivindican el valor de estos textos como documentos y como obra literaria. Precisamente, el trabajo de Humberto Guerra tiene como objetivo estudiar algunas de las autobiografías de Nuevos escritores mexicanos del siglo XX presentados por sí mismos, porque el investigador considera que ofrecen "buenos muestrarios de las preocupaciones, intereses y capacidades literarias de sus respectivos autores" (280) y porque son "textos literariamente valiosos y cuya independencia los hace posibles piezas analíticas, sin que necesariamente sean subsidiarias del resto de la obra de sus autores o que tan solo sean depósitos más o menos fieles de experiencias referenciales cuya puesta en texto no supone ninguna adherencia, ganancia o transformación por el proceso mismo de textualización" (19).

Narración, experiencia y sujeto. Estrategias textuales en siete autobiografías mexicanas se divide en tres secciones. La primera, "Perspectivas teóricas en la crítica del texto autobiográfico", ofrece una aproximación a las relaciones de esta particular escritura en primera persona con la historia, el conocimiento y el destinatario de ese discurso escrito. En el caso de la relación de la autobiografía con la historia, Guerra recuerda que la naturaleza referencial del 
texto autobiográfico lo vinculó restrictivamente a esa disciplina en el pasado. Gracias a las incursiones teóricas de autores como Philippe Lejeune, el carácter referencial de la obra autobiográfica no fue impedimento para acercarse a ese tipo textual desde otras disciplinas y desde otros marcos teóricos. La ya clásica equivalencia entre autor, narrador y personaje como definición de la autobiografía ofreció la posibilidad de reconocer que este discurso permite conocer al autor, en tanto para sí como para el otro que lo lee. Por último y gracias también a los nuevos acercamientos teóricos a la autobiografía en la segunda mitad del siglo pasado, la materia autobiográfica exhibió su valor como objeto literario al reconocerse que los elementos retóricos usados por el auto para la representación textual de sí en el texto para un otro. Finalmente, el lector desempeña un importante papel en la construcción del discurso autobiográfico, porque en aquel recae parte de la responsabilidad en la validación de los procesos referenciales, en el reconocimiento del autor como sujeto y del propio discurso autobiográfico como presentación de aquel.

Guerra hace, entonces, un somero recorrido por las posturas teóricas de James Olney, Lejeune, Elizabeth Bruss, pero finalmente propone el trabajo de William L. Howart, "Some Principles of Autobiography" como central en su análisis. Howart reconoce dos modalidades del discurso autobiográfico: la dramática y la poética. La primera es un discurso de alta referencialidad y en el cual el autor está propenso a desaparecer en los hechos que narra o funciona como testigo de estos; en la autobiografía poética, la referencialidad se vuelve ficción y los intereses del autor se dirigen hacia sí mismo como sujeto de análisis en el contexto que lo contiene. De este modo, al seguir la distinción de Howart, Guerra presenta dos secciones para estudiar los grupos autobiográficos que considera representativos de cada modalidad.

La segunda parte de Narración, experiencia y sujeto, "La existencia como espectáculo: las autobiografias de José Agustín y Carlos Monsiváis”, está dedicada al análisis de la autobiografía dramática. En el par de textos que estudia aquí, Guerra encuentra que el sujeto del discurso posee rasgos que lo caracterizan 
y que son constantes inmodificables durante el discurso, es decir, pareciera que el autor siempre ha sido quien es en el momento de escribir su vida. Este hecho, la permanencia del sujeto, hace que este funcione como testigo de los hechos que le tocaron vivir y su personalidad se afina con el tiempo, más que degradarse. Los recursos con los que se presenta el sujeto son variados: "la narración dramatizada, la dialogación y el registro de habla, la necesidad de una presencia lectoraespectadora (para cumplir cabalmente con el acto artístico y comunicacional) y el uso de la ironía como estrategia textual que facilita un punto de vista específico" (67). Cada uno de estos aspectos será estudiado y ejemplificado en esta sección.

Sobre la narración dramatizada, Guerra apunta que se trata de un recurso con el cual el autor reconstruye tiempos y espacios donde él y otros participan, pero la habilidad para la descripción de las circunstancias resulta de tal factura que se asemeja al discurso teatral, con la consecuencia de que la identidad del autor se diluye al ser él uno más de los personajes que interactúan en esa escena. Consecuentemente con este carácter teatral, José Agustín y Monsiváis trabajan en la reproducción fiel de la oralidad de la situación presentada con consecuencias como la contextualización del hecho referencial gracias al habla y el dinamismo que adquiere la escena construida. La teatralidad autobiográfica evidencia la conciencia de los autores de que hay alguien que los lee, alguien que los observa; ante ese lector, los autores se presentan como artífices de las escenas y como sujetos extraordinarios de los acontecimientos que reconstruyen. Sin embargo, los autores no ocultan su participación en momentos conflictivos, pero esto solo sirve para reforzar su imagen superior y extraordinaria, ya configurada al parecer desde el principio de su vida, y para ironizar sobre los problemas de los que han salido siempre avante.

La tercera y última parte del libro de Guerra aborda la biografía poética. En "El texto como territorio experimental: las autobiografías poéticas de Salvador Elizondo, Juan García Ponce, Sergio Pitol, Vicente Leñero y Juan Vicente Melo”, se enfatiza la naturaleza literaria de los textos seleccionados gracias a usos particulares de recursos retóricos y la configuración del sujeto como una naturaleza 
inestable y, por ello, digna de un análisis más íntimo. Se trata ahora de cinco textos que demuestran el poder cognoscitivo del discurso autobiográfico, porque los autores exploran sus vidas en busca de respuestas para ellos, antes que para el lector. Los recursos utilizados para construir estos textos son, a juicio de Guerra, tres: la imagen, su autoconsumo y el despeje de una interrogante.

La construcción de imágenes más que de escenarios sirve a estos autores para hacer de su persona un sujeto de análisis, aunque muchas veces no hay una explicación del significado de dicha imagen. Asimismo, el destinatario de estas imágenes y de la referencialidad que las acompaña no está dirigida en primera instancia hacia el lector externo, como ocurría en los casos de José Agustín y Monsiváis, sino hacia los propios autores como analistas de su pasado: exploran su memoria en búsqueda de una respuesta existencial. Este análisis de su persona y de su pasado suele centrarse en cuestiones como "La vocación literaria, su origen, su calidad, su capacidad de dar sentido a una existencia" (161), lo cual no deja de trasminar cierta dosis de angustia en los textos.

Guerra hace un pormenorizado estudio de cada uno de los textos autobiográficos que analiza en la segunda y tercera parte de su libro. Su análisis da cuenta oportunamente de ejemplos con los que se demuestra la naturaleza de las varias categorías teóricas que estudia para las autobiografías dramática y poética. Lo más loable, a mi parecer, es que Guerra consigue un singular equilibrio entre la teoría y su lectura crítica, porque siendo William L. Howart el marco teórico más importante, es siempre el texto autobiográfico del que se parte y al que se vuelve para señalar el funcionamiento estructural y temático de los materiales estudiados. Las observaciones de Guerra sobre el género autobiográfico evidencian la necesidad de acercarse de otro modo a este tipo de textos, que conservan una riqueza de significados, por un lado, en relación con el ámbito de producción en el que surgen y, por otro, en relación con los autores que las producen. Este segundo aspecto me parece que quizá es el más importante de Narración, experiencia y sujeto. Estrategias textuales en siete autobiografías mexicanas: la autobiografía arroja luz sobre estos siete escritores, sobre su 
naturaleza como seres humanos y, en consecuencia, sobre su propia obra. Me parece importante este logro del trabajo de Guerra porque insiste en la necesidad de explorar la producción referencial como parte de la producción artística, sin que esta se supedite a aquella, como suele hacer cierta corriente psicologista en el ámbito de los estudios literarios. Las siete autobiografías aquí estudiadas simplemente demuestran otra faceta de los creadores, una que resulta de particular utilidad porque proponen revivir al autor -tantas veces descartado en aras de la obra- y ponerlo siempre en relación con el resto de su producción artística. 